\title{
2. Russia's energy via a spatial prism: energy flows in a mycelium of power
}

In this chapter I look at Russia's energy as a relational space. I scrutinize flows of hydrocarbons, coal, and different renewable energy sources across geographical space - not in the absolute terms of tonnes and cubic metres, but based on their 'ability' and usability to form economic, political and societal ties and power-vested practices. Thus, in this chapter I lay out the conceptual toolkit this book builds on - in other words, this chapter brings together energy spatialities, materialities and power. I also introduce the concepts of hydrocarbon culture and energy superpower, which are central to understanding how fossil energy and political power are intertwined in Russia.

\section{THE PROBLEMATIC SPATIALITIES OF HYDROCARBONS}

Geographers have argued that the non-territorial and point-like nature of hydrocarbon production is a major cause of several shortcomings in the social and environmental responsibility prevailing in energy producer states (Watts 2004a, 2004b). Oil and gas are produced in specific locations, points in a geographical space, and then transported to consumers via narrow strips called corridors. Although modern societies are 'soaked' in oil and gas, and we have become chronically dependent on them, after all hydrocarbons 'touch' the Earth very little at the production end of the commodity chain. Of course, consumption and (mal)practices in the hydrocarbon industries ensure that oil and gas cover the whole planet in the form of soot, sulphur, nitrogen, volatile organic compounds and carbon dioxide emissions. The very fact that hydrocarbons 'touch' the ground so selectively and, especially in the Russian case, are located in the peripheries away from communities and society at large is a factor producing negative path dependencies. Bridge (2010, pp. 527-8; 2011, pp. 317-19) argues that, in essence, there are several 
ways in which the materiality of oil (and gas) produces crisis situations within the normal functions of the industry, as listed in bullet points below. Here the materiality of hydrocarbons refers to those concrete material artefacts, such as oil development infrastructure and gas transit and distribution pipelines, as well as less tangible but still material forms of substance like oil and gas deposit geology, air pollution and greenhouse gas emissions.

- The discrepancy between hydrocarbon resource geology and the colossus structure of the oil industry produces a landscape of leapfrog development as small fields are neglected. This has led to a focus on mega deposits located in more extreme environments and depths - with the related dire environmental and social costs.

Russia's hydrocarbon companies, Gazprom and Rosneft in particular, are among the biggest in the world. For example, these two parastatal companies have been granted a monopoly in oil and gas exploration and extraction in the peripheral offshore Arctic and in some East Siberian fields. These two major greenfield energy provinces are even more detached, if possible, from Russian society than the brownfields of today. In the Russian case, this leapfrog development - the large volumes of unearthed oil and gas that remain in less opulent deposits in the brownfield energy provinces of Volga-Urals and Western Siberia - is thus tied to the structure of the industry, as suggested by global theory. As a result, the hydrocarbon energy geographies strengthen the fatal connection between authoritarian rule powered by peripheral resources, and uncontrolled by society.

This reasoning on the spatial effects of the hydrocarbon commodity chain is partly based on the arguments expressed in theoretical discussions of the resource curse, or paradox of plenty. The perspective emphasized here refers to those spatial effects that are related to internalizing non-renewable resources as infinite. That means that this distinctive resource curse mentality (Tynkkynen 2007; Watts 2004b) functions as a catalyst for exacerbating the territorial effects. This mentality produces a combination of discourses and practices to uphold a distinctive political setting that dwarfs all sectors of the local economy except those based on hydrocarbons. In the Russian case, the social cost is the further encouragement of environmentally unsustainable and politically unaccountable practices.

- A 'systemic leakage' of carbon along the hydrocarbon commodity chain produces environmental and social problems ranging from 
upstream developments to downstream use and from the local to global level, for example, from human health problems caused by ambient air to global climate change.

The most problematic and seemingly endemic adverse material dimension of hydrocarbons is probably the social and environmental effects of the 'systemic leakage' of carbon. Russia is a prime case embodying a wide range of emissions within and throughout its hydrocarbon commodity chains. Russia is not the biggest polluter of the climate, as its greenhouse gas emissions, some 2000 million tonnes of $\mathrm{CO}_{2}$ equivalent (emissions + $2644 \mathrm{Mt} \mathrm{CO}_{2} \mathrm{e} / \mathrm{y}$, carbon sink (forests etc.) $-634 \mathrm{CO}_{2} \mathrm{e} / \mathrm{y}$ ) put it fourth among polluters after China, the United States and India (Climate Action Tracker 2018). However, Russia does unfortunately well on this list with regard to all other 'records'. Russia has the most oil pipeline accidents, an estimated 15000 to 20000 per year. When combined with leakages in oil production and refining, this represents between 1.5 and 5 million tons of oil - up to 1 per cent of production released into the environment (for example, Thompson 2017; Vasilyeva 2014). Russia's hydrocarbon industries are flaring - burning without using the energy content - the associated petroleum gas, somewhere between 10 and $20 \mathrm{bcm}$ per year. The vast range of estimates concerning these emissions tells a grim story: the hydrocarbon-dependent regime of Putin is unable to exert environmental control over the polluting industries. Methane emissions in oil and gas production, and also during gas transportation, continue to be a black box: there is no reliable and transparent data or ongoing research regarding these emissions. The sheer size $-40000 \mathrm{~km}$ of pipelines inside Russia - of the gas transportation system is a sign that we need credible knowledge about emissions along the hydrocarbon chains.

Furthermore, the costs of pollution along the hydrocarbon commodity chain are predominantly borne by those who do not enjoy the wealth and power produced by the commodity trade (Bridge 2011, pp. 318-19). In other words, the flow of hydrocarbons through societies produces a cumbersome conflict in which the economic prosperity and growing affluence of one group produces externalities, such as environmental and health problems affecting people and communities in a less privileged socio-economic situation. Campbell (2003, pp. 439-40) argues that the inability to address this conflict from local to global contexts is the most important barrier to sustainable development and also poses a severe security threat.

Chapter 5 looks at the effects of leapfrog development and the systemic leakage of carbon through the Russian Arctic context, and 
Chapter 6 is devoted to the narrative being built by the hydrocarbondependent regime in an attempt to justify why the global carbon problem is something Russia and Russians should not worry about.

- The molecular logic of hydrocarbon production produces societal power from the ability to control oil and gas wells, not from administering the territory. Hence, the 'geography of holes' promotes the logic of violence and possession, making it difficult to embrace justice and democracy.

This spatial dimension of a hydrocarbon-dominated Russia is the key to understanding the resource-driven push towards more authoritarian rule. Russia has always been economically dependent on resources of the periphery, so it is no surprise that this spatial drift towards resources has also been called internal colonialization (Etkind 2011). The resources have been and continue to be detached from Russia proper, the densely populated European and Southern Siberian areas, just as the resources of Africa and Asia were detached from the European colonial centres. In Eurasia, they were separated by swamps, rivers and forests rather than oceans as was the case with European colonial pursuit. During tsarist times and the Soviet era, when extractive industries focused initially on commodities such as fur and timber and later on ores, coal and precious stones, the regional geographies of extraction were less dominated by point-source production and employed proportionally more people than is the case today in the oil- and gas-dominated economy of Putin's Russia. Large workforces and resource geographies were more closely linked to local communities, which meant that governance and the logic of power were different. For example, the democratizing and decentralizing factor in the late-tsarist period was grain - a territorially and subsequently non-point-source produced resource that was in high demand both at home and abroad. The spatial extent of the resource, grain, which was the most valuable export commodity of pre-revolutionary Russia, dictated that the production, harvest and transportation of it was intertwined with the society and its local communities, villages, towns and cities. The Empire did try to resist the decentralizing force of agriculture by serfdom, but it was the self-governing local body of obshina or mir in the grain-producing areas of Russia that started the decentralizing and democratizing process from the bottom up soon after serfdom was abolished (for example, Dalmatovskii monastyr' 2016). The hydrocarbondominated economies and geographies of today have no such force 
pushing for the decentralization of economic and political decisionmaking, and thus no potential for the emergence of a real federal governance structure.

- Flows of hydrocarbons from upstream production areas to consumers produce a 'horizontal choke-point geography', as securing high-value and energy-intensive hydrocarbon transport corridors, such as pipelines, generates significant opportunities for control.

The fact that oil, and especially gas, is delivered to consumers within Russia and abroad via controllable corridors that are wide-ranging but small in number is a feature that allows energy to be used as a political tool in domestic and transnational realms alike. The potential for political leverage via energy flows and infrastructures would not be so strong without state control of the pipelines. However, both oil and gas pipelines in Russia are controlled by the state-owned companies Transneft and Gazprom, respectively. This provides extensive opportunities to exert power via energy flows within Russia by utilizing both soft, alluring and hard, coercive, means.

Both the vertical and horizontal dimensions of hydrocarbon flows promote an understanding of geographical space as controllable flows of resources, not as a territory of communities. Using Castells' (1999) concepts of the spaces of flows and places, this implies that the hydrocarbon commodity chain accentuates the space of resource flows over the space of personal and communal locations. For example, just like oil and gas pipelines, highways and airports are seen more as spaces of flows with attached rules, while residential areas are pictured as spaces of places resisting the rules associated with spaces of flows. Interestingly, as we shall see in this book, state-dominated oil and gas companies in Russia attempt to construct a new kind of sense of belonging to place and community by using the materiality of hydrocarbons as the basis for this cultural and political construction. I argue that this construction aims to build a hydrocarbon culture. All in all, control of crucial energy flows is, in a world highly dependent and intertwined with these flows, a tool any empire would desire. However, this power as it conflicts with the global normative must of decarbonization - comes at a cost: low resilience of the regime due to unsustainability and the narrow base of the chosen economic policy.

Chapter 3 examines the real-life effects of hydrocarbon geographies of horizontal 'choke-points' and vertical 'holes', for example, how energy is used as a tool in maintaining Russia as a unitary state. In the transnational context, energy as a geopolitical tool is as much a discursive as 
a practical issue, and the narrative of energy superpower is unfolded in the following, whereas Chapter 4, illustrated by Finnish-Russian energy trade and diplomacy, analyses the practical issues of energy as a foreign policy tool.

\section{HYDROCARBON CULTURE IN THE MAKING}

Putin's Russia is highly dependent on fossil fuels and other nonrenewable natural resources. Since Putin's re-election in 2012, we have seen a more conservative, authoritarian and assertive Russia (Gel'man and Appel 2015), with an economic policy that increasingly relies on the fossil energy sector. These developments also explain the change of tone on climate change and strengthening link between fossil energy and Russian identity. Thus, changes in political emphasis go hand-in-hand with the need to define Russia as a 'hydrocarbon superpower' (Bouzarovski and Bassin 2011). An energy superpower is a country that is able to influence the political choices of other countries through energy exports, by producing dependencies via energy infrastructures and economic benefits generated by the energy trade. The means are thus both coercive and alluring, hard and soft. Discussion of whether Russia is an energy superpower culminates in the question of how Russia has used energy as leverage in foreign policy with regard to the main customers for Russian energy, chiefly Russia's Eastern European neighbours and the EU.

The main claim in my book is that energy wealth and power has been turned into a tool for identity construction in Russia - a hydrocarbon culture in the making. Thus, the economic and political dependence on fossil energy is profound in nature, also encompassing the spheres of culture and identity. This concept makes it easier to understand not only why fossil energy is an identity issue, but also why energy is utilized as leverage in domestic and foreign contexts, and why responsible climate policies are not an option in Putin's Russia. However, it must be remembered that the political and economic elite of Russia is probably very aware of the economic problems related to hydrocarbon dependence and the narrow base of Russia's economy. The people perceive that this dependence - exporting raw materials and importing goods - means Russia is easily seen as a developing nation, which does not fit in well with the great power frame that is the very heart of the Russian national identity. However, as Rutland (2015) deftly shows, most Russians simultaneously perceive the country as an energy superpower: the weakness of 
a one-sided economy is turned into a strength. As a result, the abovementioned identity construction tool that depends on energy and power has to be used consistently if Putin's regime wants to strengthen Russia's superpower status on the basis of hydrocarbons.

I use the concept of hydrocarbon culture, but similar notions have been developed by other scholars interested in the intertwining of energy, power and culture in Russia. Ilya Kalinin (2014), Douglas Rogers (2012, 2015) and Peter Rutland (2015) have inspired others to engage in similar research with versatile empirical approaches. My own take on the hydrocarbon culture in Russia relies on my research dealing with the materialities of hydrocarbons (gas), and how they feed into the national identity of Russians as citizens of an energy superpower. This power projected via international gas pipelines and a military vocabulary forms the core of the ability to do harm in the domestic arena as well: gas energy, infrastructure and the gas industry are defined and viewed in a manner that underscores the submissive role of individuals and communities. The specific ways of thinking and strategic technologies of rule are brought together to build a specific governmentality of a hydrocarbon culture.

The governmental mentality of hydrocarbon culture reflects many conservative objectives of the state and the regime, but by far the most important of these is conservative economic policy relying on the extraction of natural resources and fossil energy. Hydrocarbon culture can thus be seen as a tool to prevent popular criticism of economic policies that resemble those of developing states, and the chosen economic system - one that is increasingly dependent on the hydrocarbon sector and in which Russia's role in the global trade is merely that of a raw material provider, an 'energy-producing appendage' of the West. As Rutland (2015) argues, despite the fact that the majority of Russians consider their country an energy superpower, most simultaneously oppose the wealth enjoyed by the elite and created by the energy trade while many Russians live in factual energy poverty. Therefore, one motivation to come up with discourses and practices that valorize hydrocarbons is the need to change this impression and fortify the position of Putin's regime. This hydrocarbon culture in the making not only fortifies economic and industrial policies and prevents their modernization, it also advocates authoritarian, non-democratic rule and the regime's Great Power ambitions throughout Russia. Thus, despite the fact that weaving energy and natural resources into the social fabric of the society might have its positive sides, for example, in the form of eradicating energy poverty in the countryside via the national gas 
programme, the implications of the practices I have observed in contemporary Russia do give rise to more worrying thoughts. For example, the amalgamation of the needs and rationalities of the fossil energy sector and the domestic and foreign policy interests of the current regime provide grounds to argue that fossil energy, energy infrastructures and the versatile 'epiphytes' attached to it have allowed the state to construct and maintain black and white, nationalistic identities. These normalizing identities make it possible to curtail modernization of Russia's economy, suppress political opposition in Russia, and build an illusion that everything and everyone in the international arena opposes Russia.

Hydrocarbon culture is also the antithesis of a sustainable Russia. Due to domestic and international factors, the need to follow international environmental objectives has diminished and Russia's image as a responsible energy producer is of less concern than before. This leaves room for the temptation of downplaying climate policy objectives and promoting identities based on hydrocarbons and fossil energy. In fact, the climate-denial discourse (see Chapter 6) and hydrocarbon culture being promoted are only two sides of the same coin: in a nation that sees itself intertwined with the semiotics, materialities and wealth creation of fossil energy (e.g. Kalinin 2014; Tynkkynen 2016a), the impetus to be at the forefront of climate politics is a very unlikely choice. Moreover, the emerging energy culture of a fossil giant is attempting to monopolize and distort the environmental agenda, which is in practice transforming it into a social taboo. We see examples of this on the regional level, where state energy giants are inhibiting the development of more sustainable energy and environmental policies and in the nationwide propagation of climate denial narrative in the state-controlled media. In addition, the heightened confrontation between Russia and the West, including economic sanctions that target the energy sector, emphasizes the Russian need to distinguish itself in all possible ways from Western-backed agendas. Thus, as climate change is elementarily linked to the economic base of contemporary Russia and the political power of the ruling regime, in other words fossil energy, it is no surprise that this geopolitical situation makes it appealing to define the issue via sovereignty and national identity.

In summary, it is unlikely that Russia will show leadership in global climate politics and be at the forefront of efforts to cut emissions. If Russia leads or behaves as a compliant student in global climate policies, it is because of Putin's regime's foreign policy interests (for example, to subordinate China), not because there is strong civic opposition among Russians towards Putin's economic, environmental and foreign policies. Therefore, in the near future, another important issue to follow in this 
field is the way environmental awareness and civic environmental activism is handled by Putin's regime and its fossil energy entourage. An interesting case to follow is 'The Year of the Environment 2017', and similar environmental agendas of the Russian state. More specifically, how do state organizations, such as the Russian Geographical Society, try to use the framework of such projects to channel and control civic sentiments and empowerment in the realm of the environment and nature? Judging by the choice of the projects promoted and financed under the guise of the Year of the Environment 2017, it seems that the focus is very local: the majority of projects promote household waste and waste water management, and also aim to curtail industrial pollution. Despite the fact that there is a category of projects called 'The Arctic and Climate', none of the projects addresses climate mitigation per se. This shows how the regime prioritizes environmental change that is visible to Russians (waste, air pollution) while ignoring the global environmental change that will have much more severe impacts on Russians and Russia. Once again, this seems to remain in the realm of a taboo for the regime.

\section{THE (POTENTIALLY) GRATUITOUS SPATIALITIES OF RENEWABLES}

In terms of renewable energy, the research by Zimmerer (2011) and Bailis and Baka (2011) suggests that the spatial effects of this activity are predominantly positive. As bioenergy is among the most spatially extensive renewables, and thus has potentially wide positive societal and political effects, it stands out as a good example to unfold these effects. Despite the fact that the energy return on investment - the EROI ratio of most bioenergy carriers is not that good, the $\mathrm{CO}_{2}$ emissions caused by harvesting and refining are predominantly low (Font de Mora et al. 2012). This implies that the 'systemic leakage of carbon', at least in a global perspective, does not take place in the bioenergy commodity chain, as the carbon released into the atmosphere is recycled in the form of new growth. However, the production of bioenergy causes different environmental effects that can diminish biodiversity in the area of production (Afionis and Stringer 2012, p. 116) and increase air pollution at the consumption end of the chain (Haluza et al. 2012). For this simple reason, the environmental effects of the production and use of woodbased bioenergy are relative to the harvesting techniques and re-cultivation practices prevailing in the area of origin, in addition to burning technology solutions. The same applies to the notion of the leapfrog development that the hydrocarbon industry has been accused of 
- bioenergy can be produced in both ways: by overharvesting and by sustainable practices aiming for a sustained yield. The same applies to other renewables, such as solar and wind power: the climate effect of renewables is dependent on the overall sustainability of production and commodity chains. For example, metal extraction requires a lot of energy and other natural resources are needed to construct wind and solar power infrastructures, even though the production itself is carbon neutral.

The resource flows and territorial logic associated with wood-based bioenergy are considered to enhance security in production areas and, in the long run, between the energy supplier and buyer, since wood harvesting, thinning and re-cultivation affect large spaces and a multitude of communities. As a result, bioenergy production employs far more people in the area of origin than hydrocarbon developments. This is seen as promoting stability and security, and since large-scale changes in the living environment and the effects on local economies politicize resource use issues, they lay the foundation for political activity and for people to engage in decision-making. This is the argument that the EU has endorsed in the EU-Russia energy dialogue (European Commission 2011b), claiming that imports of bioenergy from Russia increase stability and security between the partners via these positive territorial effects. The same applies to other renewables, but with a slightly different logic stemming from the fact that renewable energy commodities have differentiated spatial characteristics along the commodity chain: up-, mid- and downstream. For example, 'prosumers' can produce solar power on rooftops, yet providing output in kilowatts as opposed to centralized solar power plants with capacities measured in tens of megawatts. Their spatial constellations are naturally very different, and thus also their potential to intertwine with the society and produce (positive) political and institutional effects. The same applies to wind power: mega-sized offshore wind parks owned and operated by transnationals naturally have a very different connection to communities in comparison to windmills run by co-operatives in the densely populated countryside.

In general, however, the transition away from centralized fossil energy systems towards more decentralized renewables will entail major societal changes in the future. Scholten (2019) lists six major geopolitical implications of the transition to renewables on a global scale. First, geographically more dispersed energy production based on renewables weakens monopolies and oligopolies and strengthens competitive markets via an increase in the number of actors. This means that monolithic and gigantic hydrocarbon industries will be replaced by agile, small and medium-sized renewables businesses. 
Second, the transition to renewables will decentralize energy production: large-scale power plants will be mostly replaced by household, enterprise and community level energy production infrastructures. This decentralization via renewables will promote democratization on the local and regional level, and also sow the seeds for potential separatism. The latter is surely viewed as a real threat in Putin's Russia, where centralized fossil energy is currently used as the 'glue' to maintain the centre's control in the periphery, Moscow's reign over the provinces.

Third, dependence on critical minerals (rare earth metals) within the renewables business, notably solar power, changes energy geopolitics. For example, China is the indisputable leader in producing rare earth metals with over 100 billion tonnes per year, whereas Russia stands in third place, only producing 3 billion tonnes (Kay 2018a). However, when deposits of these much-needed minerals are examined by country, China is again the leader with 44 trillion (million million) tonnes, but Russia's reserves of 18 trillion tonnes are nearly half of the level of China's resources (Kay 2018b). As the reserves of these metals are concentrated in only a few countries, they expose these countries to a similar risk of the resource curse as hydrocarbons are inducing today. However, the impact on democratization and fostering stronger official institutions is very different, as the energy production infrastructures of solar photovoltaic production are far more decentralized.

Fourth, a world dominated by renewables is an electric world. Energy systems will be based to a large extent on electricity, as transport is switching from hydrocarbons (gasoline, diesel, kerosene, etc.) to electricity, and coal and eventually gas as a commodity in electricity production will be replaced by solar, wind, hydro and geothermal energy. This entails the regionalization of energy relations - we are seeing a partial retreat from and shrinkage of global networks to make room for regional networks and grids. As Scholten (2019) argues, regionalization will be fostered by fear of dependence that will probably lead to little interconnection between grid communities. However, the economic and energy security incentives provided by supra-regional grids will probably push national and regional electricity grids to form larger entities. The target of larger grid communities also produces interdependencies that have a 'pacifying' effect on all actors. For example, the benefit of connecting the electricity grids of the EU, Russia, Central Asian countries, China and India - the major producing and consuming areas of the whole Eurasian space - is that the super-grid would act as a storage facility. This would be especially important when hydropower and new energy storage media are harnessed as adjusting power sources to benefit the whole grid, thus making it possible to balance supply and demand in an economically 
viable way. Therefore, the inherent problem of natural fluctuation in solar and wind power production would be buffered due to the super-grid's ability to sequence production and consumption over a territory of 12 time zones. From the geothermal Iceland to the solar-powered North Africa and Middle East (NAME) region, and from the European Atlantic coast over the Alps, the Urals and the Himalayas all the way to the Pacific - a west-east zone with high potential for both wind and solar power - the super-grid will connect people, businesses and nations.

Fifth, increasing the share of renewables will change the nature and volume of energy trade: instead of transporting commodities globally, electricity that is produced in a decentralized and highly localized manner will be transported regionally. Sixth and finally, this will cause creative destruction in global energy markets. It is clear that today's (fossil) energy importers are leading this process and exporters are lagging behind. The crucial question is: are the exporters, like Russia, that are highly dependent on sales of fossil energy, capable of reinvesting the affluence they create with fossil energy in renewables?

\section{FROM BIOPOLITICAL TO ENERGOPOLITICAL GOVERNMENTALITY}

Governmentality, as initially articulated by Michel Foucault in the 1970s, is a collective way of thinking about different modes of governing, and especially a government's relationship to the governed (Dean 1999; Foucault 1991). Scholars have used the concept of governmentality to study far more than state-defined systems of government, applying it also to non-governmental actors, such as companies and civil society organizations (Rivera Vicencio 2014; Rooker 2014). Governmentalities can be understood by simultaneously studying the practices that amalgamate actions and collective modes of thinking about government prevailing in a particular location, institution, or state. Thus, governmental practices consist of both words and deeds, regardless of whether or not they are conscious or intentional. In any given context, certain actors are better positioned than others to promote their rhetorical and material visions of government, which give rise to dominant discourses that come to represent certain truths, or, as Foucault (2008, p. 35) terms them, "regimes of veridiction". A question posed by the governmentality literature, therefore, is how both the conscious and unconscious 'truth' construed by dominant discourses is produced as part of governmental practice (Mills 1997, pp. 2-8). The analytics of government are defined by three central dimensions: power, truth and identity (Dean 1999, p. 18), 
and producing these requires expertise, imagination and tactical skills (Foucault 1991, p. 87).

Foucault's dynamic understanding of power and its explicit interest in discourses and practices, and the focus on strategic thinking and action, or governmentality, of those in positions of power, is well-suited as a companion for studying the entanglement of the social and the natural/ material within the realm of energy. According to Moss, Becker and Gailing (2016), the Foucauldian dispositive, a context where governmentality functions and can be analysed, includes the agency of inanimate objects and artefacts, but it does so via the discursive: materiality becomes interesting only through the discourse, that is, after being given meaning within the social. Foucault's original dispositive referred to a "heterogeneous ensemble" that brings together discourses, regulations and "architectural forms" (Foucault 1980). Thus, although the material and spatial dimension within the whole Foucauldian power-analytics field may not be central, there is a firm body of theorizing on that front, as well (Crampton and Elden 2007).

In this book, I consider Russia's energy policies, for example, the all-Russian gas programme executed by Gazprom, Russia's energy diplomacy in the transnational context and knowledge production practices related to climate change, as a manifestation of the two interrelated aspects of discourse. The first is the action, as exemplified in the national gas programme Gazifikatsiya Rossii and the statal agenda of the 'Year of the Environment 2017', which are designed to tell the story of supposed popular approval of the social responsibility strategy of the state and its champions. Second, the discourse concerns the collective 'mentality' prevailing in energy companies and the energy sector, which are closely tied to the actions and thinking of President Putin's regime. In liberal societies, governing operates primarily through biopolitical tactics because disciplinary power contradicts its core principles of individual liberty. In a system defined by biopower, the population living in the territory of the state is subjugated to techniques that have the goal of optimizing its health, welfare and life (Dean 1999, p. 20). Therefore, biopolitical governmentality has to be seen as an inseparable part of the logic of the actions of neoliberal states, including Russia. A significant body of literature now exists on Soviet and post-Soviet governmentalities (e.g. Kharkhordin 1999; Matza 2009; Prozorov 2014). However, these studies are confined in one pivotal manner: they do not look explicitly at the material and spatial in their analysis.

Stephen Collier's (2011) Post-Soviet Social, in contrast, takes an explicitly material approach. He argues that post-Soviet Russia is a prime example of a country where, stemming from the Soviet-era objectives 
and norms, the objectives of both the social welfare state and classical liberalism have come together to form modern biopolitical practices. $\mathrm{He}$ concurs with most analysts of post-Soviet power that governmentalities in today's Russia are neoliberal, but with a depoliticizing twist: saddling individuals with responsibilities is thought to benefit the state economy, but not to liberalize and democratize state governance. Accordingly, as Coleman and Agnew (2007, p. 332) suggest, in today's Russia we are not witnessing a leap from the goals of the modern into the aims, logic and action of the postmodern; rather, we are seeing the mutual inclusion and adaptation of these two goals. But this raises the question of precisely how these transformations are taking place. Through which networks and agencies are governmentalities being reworked in post-Soviet Russia? Given the prominence of Russia's energy economy, scholars have considered energy companies and the 'energy elite' as one of the most important objects of analysis when answering this question.

Scholars in the field of energy studies have introduced the concept of 'energopower': their traditional inquiries into material cultures are united with critical social science scholarship on power. Boyer (2014, pp. 22-3) defines energopower as "a genealogy of modern power that rethinks political power through the twin analytics of electricity and fuel". Energopower is "a discourse ... that searches out signals of the energomaterial transferences and transformations incorporated in all other sociopolitical phenomena". To search for energopower and energopolitics, then, is to search for the contingent and changing links between the governance of life and the energy materialities with which it is always intertwined. Rogers (2012, 2014), for example, examines how Russian energy companies utilize the materiality of oil and gas to build local and national allegiances, deploying their power to produce truth and identity. All modern biopolitical technologies are ultimately 'wired' into energy systems in one way or another. Energopower is an analytical tool that can help people understand how power and the materialities of energy are intertwined: it is all about how the governmental concern over energy supplies is related to both the biopolitical aims of guaranteeing the (bio)security of the population, as well as the exertion of control over populations and the production of economic accumulation by keeping energy flowing in grids and pipelines.

The concept of energopower is particularly useful, for example, when studying Gazprom's Gazifikatsiya programme (see Chapter 3), as it explicitly reminds us of the binary nature of contemporary energy systems: they both enable and constrain. Modern energy systems and their extensions (such as communal infrastructure) are a means of 
delivering amenities and of controlling the population. Taking a specifically geographic approach - I have attempted to elaborate the Foucauldian power analysis in the realm of energy via the concept of geogovernmentality - I am interested in the kind of truth and identities that Gazprom is constructing with its Gazifikatsiya programme as it expands to peripheral Russia. In this perspective, the goal is to better understand what kind of practical power, discursive truths, and cultural-political identities are constructed in and around energy flows and entangled materialities, and how these forms of political power condition our understanding of energy as a societal phenomenon. For example, my study of the Russian national gas programme describes how gas-based geo-governmentality is being created via powerful discourses (Tynkkynen 2016a). Following the logic of Margo Huxley (2007), I ask how specific resources and spatialities, and the materialities involved, act as agents as part of the discursive-practical use of power or of governmentality. The 'geo' in this approach is the deliberate use of the geographical characteristics of gas when building and maintaining the desired governmentality. The rationalities and practices of this hydrocarbon-culture governmentality function in and combine several scales: the subject is tied to territories and the nation through hydrocarbons, individuals are made responsible for the (bio)security of the population, and even the global is harnessed in legitimizing the heavy reliance on hydrocarbons.

The geo-governmentality approach can also challenge where the boundaries of energy materialities are. It is important to include not only energy infrastructure but also its 'epiphytes' - "ancillary apparatuses and infrastructures, such as sports halls" - which "potentially serve as conduits of disciplinary power" (Tynkkynen 2016b, p. 78). Therefore, this view challenges the clear-cut understanding of energy materiality reserved only for those linked to extraction, refining, transport and consumption of energy. In other words, I argue that social infrastructure built and maintained by energy companies or state ministries can be understood as a materiality of energy, especially when elementarily linked to power-vested discourses utilizing material dimensions of the energy sector as a tool in constructing and maintaining these discourses.

The cases in this book remind us of the different ways the material and the discursive constitute each other: energy materialities are not dictating the political, nor is the discursive unaffected by the agency of the material. Thus, a certain infrastructural form or physical and economic tie does not dictate the discourses - or policies and use of power. Likewise, discourses on energy materialities can reframe how we understand energy materiality. When looking at materiality-inspired energy discourses, we are also able to see how such materialities are utilized by 
those in positions of power. The important feature is that these energy constellations are maintained in the ways in which the material and the discursive constitute each other. 